\title{
Editorial: Educational Research and Why It's Important
}

\author{
Roseanna Bourke ${ }^{1} \cdot$ Judith Loveridge $^{2}$
}

Published online: 23 October 2017

(C) New Zealand Association for Research in Education 2017

The New Zealand Journal of Educational Research (NZJES) is aptly named, because the distinction between 'education' research and 'educational' research is critical. As Lingard (2013) has argued, "When we use the descriptor 'educational' attached to research, we are arguing that such research has educational or educative purposes, that is, such research is progressive in the sense of seeking and desiring to improve both education policy and professional practice in education" (p. 115). For contributors and readers of this journal, the importance of demonstrating the potential to impact on policy and practice is important. Researchers working in education typically are also interested in addressing equity issues as political and social agendas, and seeking to explore positive change for others through educational research.

Educational research can challenge and change educational policy and practice, as evidenced in the articles within this issue. Equity and justice of educational experience are important to these researchers. This is consistent with previous NZJES issues, where authors have sought to enable the voice of participants to be heard, to foreground culture, and question the status quo. In other words, for these authors, being educational through research is a critical part of having impact.

Of the eight articles in this issue, five present evidence about educational experiences, issues and outcomes for Māori, Pacific Island and Indigenous students. The approaches taken to address these questions are diverse, ranging from examining the very way that ethnicity is defined and used in statistical analysis to exploring 'the spiritual footsteps of teaching and learning'.

In the first article, Boereboom critiques the way that ethnicity is defined and then used for the purposes of analysing and reporting national educational outcomes and

Roseanna Bourke

R.Bourke@massey.ac.nz

1 Massey University, Palmerston North, New Zealand

2 Victoria University, Wellington, New Zealand 
assessment data. Although New Zealand has moved to a view of ethnicity as a fluid social construct which allows for self-identification and the claiming of multiple ethnic identities, the rapid increase in ethnic diversity and the need for narrow and precise definitions of variables for the purposes of statistical analysis are creating a range of issues that to date have been largely ignored. Boereboom explores these issues by comparing an analysis of NCEA Level 1 results using (1) the status quo of rank ordering to assign a single ethnic identity, and (2) a weighted ethnicity proportional representation approach. Boereboom's analysis and arguments show that there is the potential for current practices to mask and under report trends and thereby to strengthen a deficit approach to educational planning. He compellingly argues that there are strong ethical grounds and concerns related to validity to support a call to 're-examine the practice of ethnic priority ranking and explore alternative more culturally valid and inclusive approaches'.

Although positive outcomes have been achieved in Māori medium education over the past 40 years there are still very real concerns about the revitalisation of te reo Māori. Research is needed to support the revitalisation process. Hill's research focuses on level 2 Māori medium programmes, that is programmes with $51-80 \%$ Maori language instruction. He explores the perceptions of students and their parents about the contribution these programmes make to the education of students. In Maged, Rosales-Anderson and Manuel's article, they explore teaching and learning relationships that students attending a Wānanga (a Māori indigenous tertiary education organisation) identified as having had a positive impact on their learning and engagement in the past or currently. In particular Maged et al. are interested in exploring the spiritual element of the connection between the kaiako (teachers) and the tauira (students). They identify a range of ways in which tauira had felt a deep sense of connection through the wairua (spirit) within the classroom to the people, place and space around them and which had impacted positively on their learning and their well-being, both within and beyond the classroom.

Olsen and Andreassen explore how indigenous issues are articulated and instantiated in the Early Childhood Education Curricula (the official written documents) of Norway and Aotearoa/New Zealand. They argue that the purpose of comparing how indigenous issues are conceptualised within the respective curricula is 'to bring something new to the analysis of one case by putting it next to another'. Their analysis focuses on the main tendencies of the indigenous issues in each country. While they conclude, 'the curricula are expressions of indigenous knowledge and status being privileged' they caution that if the curricular claims and statements are not enacted, then it would not be a surprise to find the indigenous silenced.

Towner, Taumoepeau, Lal and Pranish focus on the situation of Pasifika learners in the tertiary context. They conducted a case study, which evaluated the outcomes of current practices and support for Pasifika students at a New Zealand private tertiary education (PTE) provider in order to assess what practices and support systems are beneficial for Pasifika learners. Their findings emphasise the importance of a variety of support systems, many of which increased a sense of community connectedness for students, and a culturally sensitive environment for students' academic success. 
Van Rij explores how the New Zealand's School Journal has reflected both shifting perceptions of childhood as well as acting as a mirror on the educational ideologies of the times, from the time it started (1907) through to 1918. Later, she introduces another period (1919-1938) where she identifies how the journal 'led to the liberal spirited, revised syllabus of instruction in 1935. This in turn paved the way for the curriculum reforms from 1939 into the 1950s'. In this article van Rij traverses the complex terrain of the journal by presenting the historical and cultural analysis of the type of prose, subject content and inherent political messages within the journal.

In McPhail and Laurie's article, they argue that social science research methods teaching needs to include the idea of realism. Given that interpretivism is commonly used in educational social science research, the authors were both faced with a dilemma when conducting their respective PhDs, looking for a methodological approach that could enable them 'to explain the social meaning of events and provide a means of exploring causes and processes obscured within the phenomenon being investigated'. Using the case study of the second author who completed her $\mathrm{PhD}$ using realism, this article explores what this methodological approach has to offer, and how a realist rather than an interpretivist orientation can offer a different analysis of data.

Oldham's article foregrounds the increase of non-state policy actors in public education systems. He explores the phenomenon of 'enterprise education' by using governance theory and methods to argue that this is replacing curriculum governance.

Finally Gerrard's commentary, explores the impact of the Productivity Commission's Report on New Models of Tertiary Education (2017) and how this may impact on the changing nature of the purpose and value of tertiary education.

This issue of the New Zealand Journal of Educational Studies is also our last one as Editors. Our tenure has included transitioning the journal from a print-based journal to its first online issue with Springer (Volume 50), and marking its 50th anniversary celebrations. The journal continues to be foundational to the New Zealand Association for Research in Education (NZARE) learned society, and the principal vehicle for researchers and educators to share and disseminate their published research.

Since 2014, we have edited 8 issues, which have included 65 published articles and 5 commentaries written by 112 authors (76\% female; $24 \%$ male). We extend our thanks to the 138 reviewers who gave their time, expertise and collegial support to blind peer review the work. In addition, we have published 39 book reviews and we thank our Book Editor, Dr. Stephanie Doyle, Victoria University of Wellington, who liaised so successfully with the book reviewers that we were never without a well-articulated review of the latest work coming out. During this period there have been two special issues: Student Voice 49(2), and Equity and Diversity 51(2). Both these special issues included national and international contributions, with one collection arguing the importance of including student voice in learning, policy and practice, and acting on these views; and the other on ensuring equity through education enables, celebrates and includes all learners.

Across this period the contributing authors have collectively demonstrated a broad interest in educational research, policy and practice, which fully justifies the journal's claim to be concerned with 'educational studies'. The many contributors to 
this journal have documented change and progress, issues and tensions, and promises and visions. Given this depth and breadth of educational research, and the diversity of researcher-authors, it is not surprising that their own values and ideologies are embedded in the work. As Lingard (2013) reminds us, evidencebased policy is not all about research evidence. It includes in the mix values, ideology and professional knowledge of the researchers who conduct the research, and the practitioners and policy makers who read and interpret that research.

The areas of scholarship covered over this period (Volumes 49-52) are diverse, inclusive and representative of multi-voiced, cultural and social imperatives. These include Kura Kaupapa Māori research, cross-cultural practice, the achievement gap, tertiary education supervision and partnership practices, all education sectors, the history of education in New Zealand, student voice, education policy, equity in education, curriculum design, teacher initial education and professional development and the nature of education in the twenty-first century.

This research labour has originated from within 29 institutions, including 21 universities, 1 wānanga, 2 polytechnics, independent researchers (2), and other tertiary, research or independent providers such as the New Zealand Council for Educational Research (NZCER), Kelston Deaf Education Centre, and SPELD. The research published within NZJES has demonstrated it is confidently located within the Aotearoa/New Zealand context. Locally, we have had contributors from University of Auckland, Auckland University of Technology (AUT), University of Waikato, Waikato Institute of Technology (Win Tec), Te Whare Wānanga o Awanuiārangi, Massey University, Victoria University of Wellington, Whitireia Polytechnic, University of Canterbury, and University of Otago. There has also been an international presence connected closely to the New Zealand research community, including contributions from researchers based in higher education organisations from the UK, Ireland, Sweden, Norway, USA, UAE, and Australia. The institutions represented include University of Dublin, University of Manchester, University of Uppsala, University of Troms $\varnothing$, University of Melbourne, University of New South Wales, Monash University, Australian Catholic University, University of New England, University of Denver, Bryn Mawr College, North Carolina State University, University of Florida, Southern Cross University and Zayed University.

As co-editors, we are proud to have been part of this continuing educational research journey. We wish the incoming editors the rich experience we have been privileged to have. We thank the Editorial Board for the stimulating collegial discussions at our meetings and the NZARE Council for their ongoing support. A warm thank you to all contributors, reviewers, NZARE members, and staff at Springer for enabling this journal to take the next step in its trajectory of contributing to the betterment of education in Aotearoa/New Zealand.

\section{Reference}

Lingard, B. (2013). The impact of research on education policy in an era of evidence-based policy. Critical Studies in Education, 54(2), 113-131. 